\title{
Photorelease of GABA with visible light using an inorganic caging group
}

\author{
Emiliano M. Rial Verde ${ }^{1}$, Leonardo Zayat ${ }^{1,2}$, Roberto Etchenique ${ }^{2}$ and Rafael Yuste ${ }^{1, *}$
}

1. Department of Biological Sciences, Howard Hughes Medical Institute, Columbia University, New York, NY, USA

2. Departamento de Química Inorgánica, Analítica y Química Física - INQUIMAE, Facultad de Ciencias Exactas y Naturales,

Universidad de Buenos Aires, Buenos Aires, Argentina

Edited by: $\quad$ Edward M. Callaway, The Salk Institute, USA

Reviewed by: Gábor Tamás, University of Szeged, Hungary

Karl Deisseroth, Stanford University, USA

\begin{abstract}
We describe the selective photorelease of $\gamma$-amino butyric acid (GABA) with a novel caged-GABA compound that uses a ruthenium complex as photosensor. This compound ("RuBi-GABA") can be excited with visible wavelengths, providing greater tissue penetration, less photo-toxicity, and faster photorelease kinetics than currently used UV light-sensitive caged compounds. Using pyramidal neurons from neocortical brain slices, we show that RuBi-GABA uncaging induces GABA-A receptor-mediated responses, has no detectable side effects on endogenous GABAergic and glutamatergic receptors and generates responses with kinetics and spatial resolution comparable to the best caged GABA compounds presently available. Finally, we illustrate two potential applications of RuBi-GABA uncaging: GABA receptor mapping, and optical silencing of neuronal firing.
\end{abstract}

Keywords: uncaging, inhibition, ruthenium, GABA, photorelease

\section{INTRODUCTION}

GABAergic synapses use chloride and bicarbonate ion flow to modify membrane potential. Although they are traditionally considered inhibitory, a growing body of work points towards a dual nature of GABAergic transmission. The excitatory nature of $\gamma$-amino butyric acid (GABA) is well accepted in early development, when the chloride reversal potential is depolarized (Ben-Ari, 2002; Ben-Ari et al., 1989; Janigro and Schwartzkroin, 1988), but, excitatory GABA-mediated responses have also been documented in adult preparations (Alger and Nicoll, 1979; Andersen et al., 1980; Gulledge and Stuart, 2003; Taira et al., 1997). Moreover, there is indication that at the axon initial segment the chloride reversal potential could be very different from that of the soma, and that GABAergic neurons, such as chandelier cells, could have an excitatory effect on the network (Khirug et al., 2008; Szabadics et al., 2006; Woodruff et al., 2006). Thus, the excitatory or inhibitory function of GABAergic synapses is determined by the resting membrane potential, the location of the GABA receptors, the electrical properties of the surrounding membrane, the ion buffering and extrusion mechanisms, and also probably by network states (UP and DOWN-states, sleep, etc.). Such dependencies prevent a simple analysis of GABAergic

*Correspondence: Rafael Yuste, Department of Biological Sciences, Columbia University, 1212 Amsterdam Avenue, Box 2435, New York, NY 10027, USA. e-mail: rafaelyuste@ columbia.edu

Received: 29 May 2008; paper pending published: 08 July 2008; accepted: 01 August 2008; published online: 13 August 2008.

Citation: Front. Neural Circuits (2008) 2: 2. doi: 10.3389/neuro.04.002.2008

Copyright (C) 2008 Rial Verde, Zayat, Etchenique and Yuste. This is an open-access article subject to an exclusive license agreement between the authors and the Frontiers Research Foundation, which permits unrestricted use, distribution, and reproduction in any medium, provided the original authors and source are credited. function in dendritic integration and circuit function, presenting a significant challenge for experimentalists. Overcoming such a challenge requires an approach that could in principle analyze GABAergic transmission with spatial and temporal precision bypassing the variability generated at the pre-synaptic site.

Different techniques have been used to study GABAergic neurotransmission, including electrical stimulation (Alger and Nicoll, 1979; Connors et al., 1988), GABA applications by iontophoresis (Andersen et al., 1980) or pressure injection (Connors et al., 1988), whole-cell recordings from connected neurons (Gibson et al., 1999; Gupta et al., 2000; Szabadics et al., 2006; Woodruff et al., 2006), and GABA photorelease (uncaging) (Katagiri et al., 2007; Pettit and Augustine, 2000; Rothman et al., 2007). While these techniques have been extremely useful, they all have limitations. Establishing dual recordings from connected cells is a low-yield technique and, the same as electrical stimulation, it relies on the pre-synaptic apparatus and it allows the spatial localization of the GABA receptors involved only in combination with post hoc electron microscopy. GABA iontophoresis provides some spatial and temporal control, but it requires an invasive application pipette. It is, therefore, not conducive to repetitive probing onto the same cell or groups of cells. Photo-uncaging, on the other hand, is a non-invasive technique that can provide repeatable temporally and spatially controlled liberation of GABA.

Here we introduce the use of a new ruthenium-based caged GABA compound (RuBi-GABA: ruthenium-bipyridinetriphenylphosphine-GABA) (Nikolenko et al., 2005; Zayat et al., $2003,2006,2007)$ that has multiple advantages compared to the previously available UV-sensitive caged GABA compounds. First, inorganic-based photo release is usually much faster than organic approaches (Balzani and Carassitti, 1970). Second, 
RuBi-GABA has a higher quantum yield of uncaging than CNB-GABA, perhaps the previous standard for GABA uncaging (Pettit et al., 1997; Zayat et al., 2007). Third, RuBi-GABA can be uncaged using visible light, instead of UV light and therefore enables the use of longer wavelengths, resulting in less scattering and allowing the light source to penetrate deeper into living tissue (Svaaland and Ellingsen, 1983). In applications dominated by scattering, such as imaging of brain slices or in vivo, the smaller scatter of visible wavelengths, when compared with UV, could paradoxically result in a better spatial resolution, in spite of the longer wavelengths. Finally, visible wavelength uncaging also dramatically decreases the cost of an uncaging light source making the technique available to a larger group of researchers.

We show that photorelease of RuBi-GABA produces GABA receptor-mediated currents in pyramidal neurons from mouse neocortical slices. We also characterize the kinetics and spatial resolution of responses elicited by RuBi-GABA uncaging. Finally, we illustrate two possible applications of this technique by mapping the localization of GABA receptors and by preventing action potential generation, thus optically controlling cell activity.

\section{MATERIALS AND METHODS}

\section{SLICE PREPARATION AND ELECTROPHYSIOLOGY}

$350 \mu \mathrm{m}$ thick coronal slices from 14-day-old C57BL/6 mouse visual cortex were prepared using a Leica VT1000-S vibratome with a cutting solution containing (in $\mathrm{mM}$ ): $27 \mathrm{NaHCO}_{3}$, $1.5 \mathrm{NaH}_{2} \mathrm{PO}_{4}, 222$ Sucrose, $2.6 \mathrm{KCl}, 3 \mathrm{MgSO}_{4}, 0.5 \mathrm{CaCl}_{2}$. Slices were incubated at $32^{\circ} \mathrm{C}$ for $30 \mathrm{~min}$ and then kept at room temperature for at least $30 \mathrm{~min}$ before transferring them to the recording chamber. The recording chamber was bathed in ACSF ( $\mathrm{pH}$ 7.4), kept at room temperature and saturated with $95 \% \mathrm{O}_{2}$ and $5 \% \mathrm{CO}_{2}$, containing (in $\mathrm{mM}$ ): $126 \mathrm{NaCl}, 3 \mathrm{KCl}, 2 \mathrm{MgSO}_{4}$, $2 \mathrm{CaCl}_{2}, 1.1 \mathrm{NaH}_{2} \mathrm{PO}_{4}, 26 \mathrm{NaHCO}_{3}$, and 10 dextrose. For voltage-clamp recordings, $2 \mu \mathrm{M}$ TTX, $10 \mu \mathrm{M}$ NBQX, and $20 \mu \mathrm{M}$ APV were added to the ACSF in most cases. Unless indicated, neurons were held at $0 \mathrm{mV}$ membrane potential. Whole-cell electrodes (5-7 M $\Omega$ ) were used. All voltage-clamp recordings, except those shown in Figures 2C,D were performed with intracellular solution ( $\mathrm{pH} 7.25$ ), containing (in mM): 115 Csmethanesulfonate, $20 \mathrm{CsCl}, 10$ HEPES, $2.5 \mathrm{MgCl}_{2}, 4 \mathrm{Na}_{2}$-ATP, $0.4 \mathrm{Na}$-GTP, $10 \mathrm{Na}_{2}$-phosphocreatine, 0.6 EGTA, and 0.1 Alexa Fluor 594. The voltage-clamp recordings shown in Figures 2C,D were done with intracellular solution ( $\mathrm{pH} 7.25$ ), containing (in $\mathrm{mM}$ ): $135 \mathrm{~K}$-methylsulfate, $10 \mathrm{KCl}, 10$ HEPES, $5 \mathrm{NaCl}, 2.5 \mathrm{Mg}$ ATP, 0.3 Na-GTP, and 0.1 Alexa Fluor 594. For current clamp recordings, no drugs were added to the ACSF, and pipettes were filled with intracellular solution ( $\mathrm{pH}$ 7.25) containing (in $\mathrm{mM}$ ): $128 \mathrm{~K}$-methylsulfate, $10 \mathrm{HEPES}, 4 \mathrm{MgCl}_{2}$, $4 \mathrm{Na}$-ATP, $0.4 \mathrm{Na}$-GTP, 10 Na-phosphocreatine, 3 ascorbic acid, and 0.1 Alexa Fluor 594.

We performed recordings from layer $2 / 3$ pyramidal cells using MultiClamp 700B (Molecular Devices) amplifiers, and acquired the signals through a National Instruments PCI 6259 board with custom Matlab and C++ software. All the analysis was done using custom Matlab-based software.

mIPSCs were recorded at $0 \mathrm{mV}$ of holding potential in cells voltage-clamped with cesium-based intracellular solution. Sucrose-evoked mIPSCs were recorded during the $2 \mathrm{~s}$ following a $50 \mathrm{~ms} 1 \mathrm{M}$ sucrose puff delivered with a $2.5 \mathrm{M} \Omega$ patch pipette placed at the surface of the slice, $\sim 20 \mu \mathrm{m}$ away from the cell body. To elicit action potential firing (Figure 5) we applied a sinusoidal current injection and varied its amplitude to obtain action potentials, in all trials, at the peak of the sinusoidal. All experiments were conducted at room temperature $\left(22-25^{\circ} \mathrm{C}\right)$.

\section{RuBi-GABA UNCAGING}

Images were acquired using a custom-made two-photon laser scanning microscope based on the Olympus FV-300 system (FV-300 side-mounted to a BX50WI microscope with a $60 \times$, 1.1NA, water immersion objective) and a Ti:sapphire laser (Chameleon Ultra, Coherent). Fluorescence was detected with a top-mounted Hamamatsu H7422-P40 PMT connected to a Hamamatsu C7319 preamplifier whose output was connected to the Fluoview system.

The light source for uncaging was a DPSS $473 \mathrm{~nm}$ laser (BLM-300 with analog modulation, Extreme Lasers). Images of the soma were first acquired, using $950 \mathrm{~nm}$ excitation light to prevent RuBi-GABA uncaging, at $9 \times$ or $10 \times$ digital zoom with Fluoview 5 software in XY scan mode. A peri-somatic uncaging point was selected in point scan mode. The electrophysiology software triggered the point scans with $+5 \mathrm{~V}$ pulses using the Fluoview TIEMPO module. The pulse duration was controlled from the electrophysiology software with voltage pulses sent to a custom-made circuit connected to the power supply of the blue laser. Trial automation was commanded by our electrophysiology Matlab-based software through a Fluoview Protocol Processor, and inter-trial-interval was set to $5 \mathrm{~s}$.

RuBi-GABA was added to the bath at $5 \mu \mathrm{M}$ concentration, except during the control experiments shown in Figure 1D $(20 \mu \mathrm{M})$, and Figure $1 \mathrm{~F}(1.6 \mathrm{mM})$. At millimolar concentrations we have noticed that RuBi-GABA can act as a GABA receptor antagonist and we occasionally observe reversible alterations on the input resistance of the neuron (unpublished observations). Both unspecific effects appear due to the phosphine moiety, since bath application of the phosphine alone can reproduce them. Nevertheless, at concentrations $<20 \mu \mathrm{M}$ we have never detected any effect on either membrane resistance, or frequency or amplitudes of mEPSCs or mIPSCs (see below).

RuBi-GABA is light-sensitive, so all the experiments were conducted with minimal light. The computer screens and video monitor were covered with two layers of Rosco \#27 medium red filters. To establish whole-cell access the cells were subject to oblique illumination with and IR-pass filter on top of the microscope field diaphragm, and visualized through a CCD camera (DAGE-MTI IR-1000) connected to a Sony PVM-137 black and white video monitor.

\section{RESULTS \\ VISIBLE LIGHT UNCAGING OF RUBi-GABA PRODUCES GABA RECEPTOR-MEDIATED CURRENTS}

We have synthesized a novel series of caged compounds that release active moieties, using ruthenium as the photosensor (Zayat et al., 2003, 2006). Ruthenium is a transition metal that is widely used in inorganic chemistry, due to its versatile chemistry and the ability of some ruthenium complexes to absorb light. Like other inorganic compounds that are light-sensitive, ruthenium releases ligands in a heterolytical fashion, with a single photochemical step, the photorelease is therefore clean and fast (Zayat et al., 2003).

RuBi-GABA is a caged-GABA, composed of a Ruthenium polypyridine core bearing six coordinated positions, four of 
A

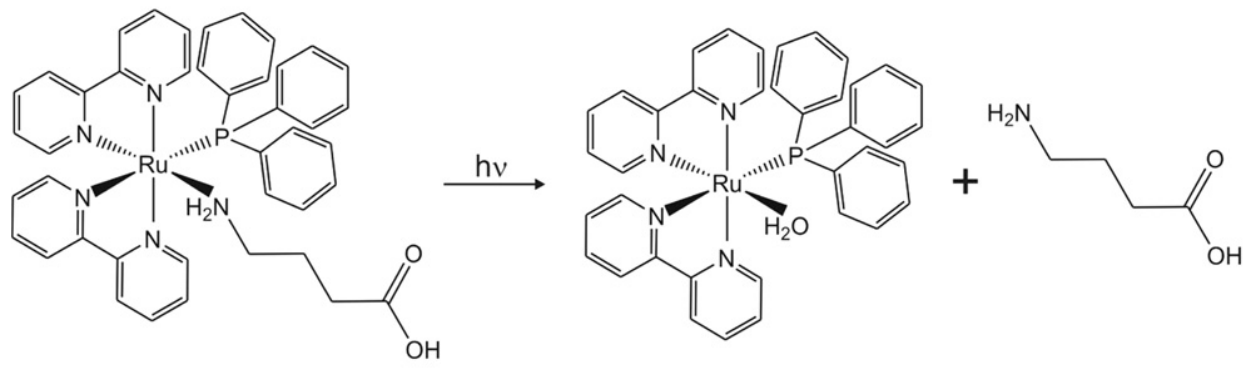

B
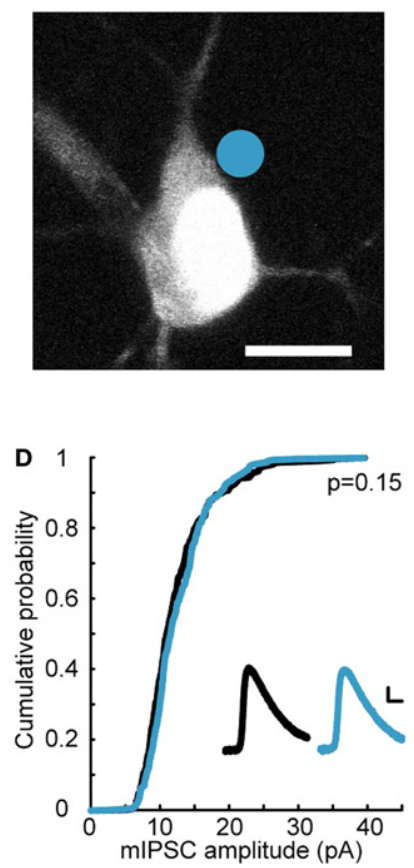

C
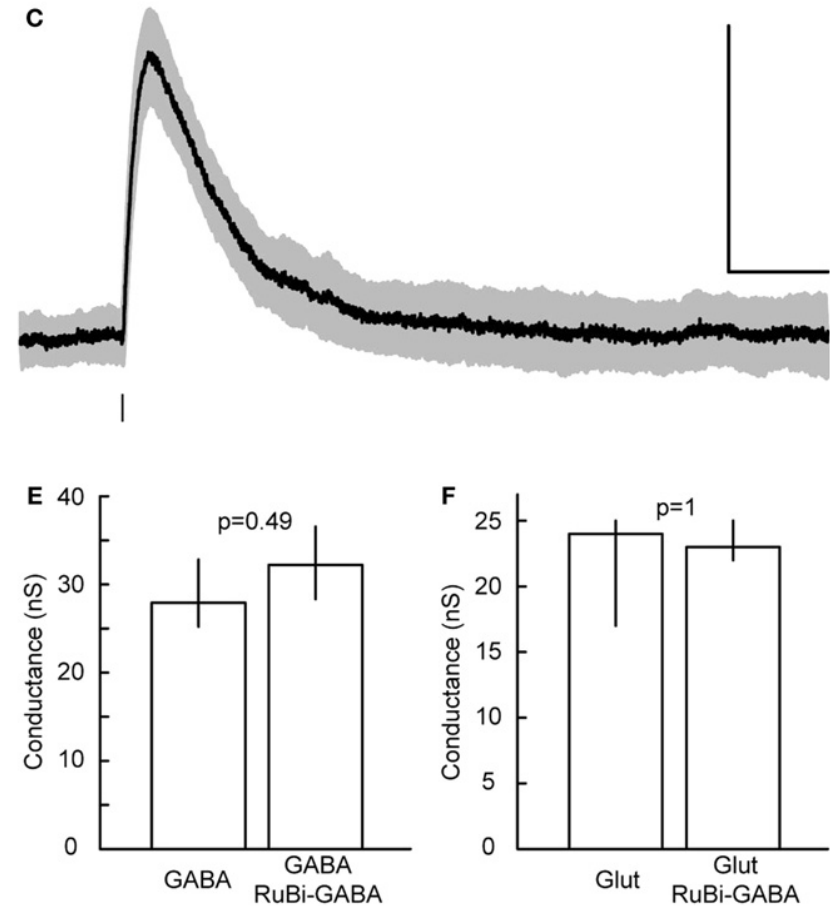

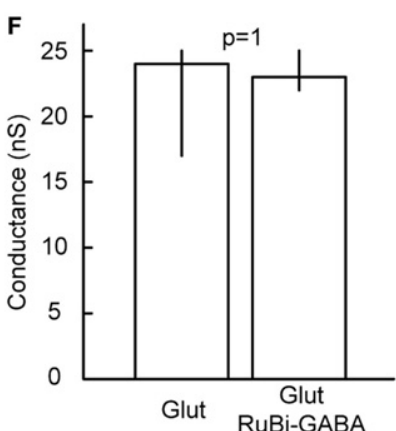

Figure 1 | RuBi-GABA uncaging-evoked outward currents without affecting endogenous conductances. (A) GABA photorelease from rutheniumbipyridine-triphenylphosphine-GABA (RuBi-GABA). (B) Example of a typical uncaging experiment, with RuBi-GABA ( $5 \mu \mathrm{M})$ in the perfusate, showing a cortical layer 2/3 pyramidal neuron loaded with Alexa Fluor 594. The cyan dot indicates the site of uncaging with $473 \mathrm{~nm}$ light. Scale bar: $10 \mu \mathrm{m}$. (C) Average (black) and standard deviation (gray) of 50 successive uncaging responses. The black bar below the trace indicates the uncaging laser pulse. (D) Cumulative probability plot of the amplitudes of $380 \mathrm{mIPSCs}$ in the absence (black), and $326 \mathrm{mIPSCs}$ in the presence of $20 \mu \mathrm{M}$ RuBi-GABA (cyan). Kolmogorov-Smirnov $p$-value is indicated. Inset: mIPSCs in the absence (black) and presence of $20 \mu \mathrm{M}$ RuBi-GABA (cyan). Scale bars: $2 \mathrm{pA}, 10 \mathrm{~ms}$. (E) Median and inter-quartile-range of conductances through the GABA-A receptors in response to GABA puffs $(200 \mu \mathrm{M})$ or GABA + RuBi-GABA $(5 \mu \mathrm{M})$. Mann-Whitney $p$-value is indicated $(n=4)$. (F) Median and inter-quartile-range of conductances through glutamate receptors in response to glutamate puffs (200 $\mu \mathrm{M}$ to $1 \mathrm{mM})$ or glutamate + RuBi-GABA (1.6 mM). Mann-Whitney $p$-value is indicated $(n=6)$.

which are occupied by $2,2^{\prime}$ bipyridines, the fifth by triphenylphosphine, and the sixth by GABA (Figure 1A). Upon absorption of visible light, it photocleaves and releases GABA. Its synthesis and chemical properties were described separately (Zayat et al., 2007), and in this study we focused in its biological characterization and applications.

We first examined the ability of RuBi-GABA to elicit GABA receptor-mediated responses in living neurons. For this purpose, we bath-applied the compound $(5 \mu \mathrm{M})$ to acute slices from mouse visual cortex, and established whole-cell voltage-clamp recordings onto layer $2 / 3$ pyramidal cells. In our initial experiments we used pulses of blue laser light ( $473 \mathrm{~nm}, 5-30 \mathrm{~mW}$ at the sample), focused at the edge of the soma of the selected neurons with a $60 \times, 1.1 \mathrm{NA}$ objective (Figure $1 \mathrm{~B}$ ), to explore the release of the compound in the visible range. We used cesium-based intracellular solution, with neurons voltage-clamped at $0 \mathrm{mV}$, to measure outward currents, hallmark of GABA receptor activation, generated after brief $(1-0.5 \mathrm{~ms})$ laser uncaging pulses (Figure 1C).

Given that caged compounds are known to behave as receptor antagonists (Canepari et al., 2001; Maier et al., 2005; Molnar and Nadler, 2000), we first ensured that RuBi-GABA did not affect endogenous GABAergic or glutamatergic transmission (Figures 1D-F). Indeed, we observed no effect of RuBi-GABA in mIPSC (miniature inhibitory post-synaptic current) amplitude at concentrations as high as $20 \mu \mathrm{M}$ (Figure 1D; KolmogorovSmirnov $p=0.15$ ). We were also unable to detect any effect of RuBi-GABA, at the concentration used all throughout our experiments, using a voltage-clamp ramp protocol to measure GABA-induced conductance (Thompson and Gahwiler, 1989) 
(Figure 1E; Mann-Whitney $p=0.49, n=4$ ). Finally, RuBiGABA did not show an effect on glutamatergic conductances, measured using the same protocol, at concentrations as high as $1.6 \mathrm{mM}$ (Figure 1F; Mann-Whitney $p=1, n=6$ ).

In all neurons tested (23 layer $2 / 3$ pyramidal neurons), somatic uncaging of RuBi-GABA generated outward currents. The observed currents reversed at the expected chloride reversal potential of $-43 \mathrm{mV}$ (Figures 2A,B), indicating that these currents were likely due to activation of GABA-A receptors. Due to the somatic location of the uncaging site, we expected GABA receptor-mediated currents dominated by the chloridepermeable GABA-A receptor with little or no contribution of potassium currents elicited upon activation of GABA-B receptors. To explore this directly, we switched to a potassium-based intracellular solution with slightly depolarized $(-40 \mathrm{mV})$ chloride reversal for the next experiment, finding that RuBi-GABA uncaging-induced currents were inward when recorded at $-70 \mathrm{mV}$ of holding potential (Figure $2 \mathrm{C}$ ), and were reversibly abolished by addition of the selective GABA-A receptor antagonist gabazine $(20 \mu \mathrm{M})$ to the bath (Figures 2C,D). These experiments demonstrated that RuBi-GABA uncaging can activate GABA-A receptors.

\section{KINETICS AND SPATIAL RESOLUTION OF RUBi-GABA UNCAGING}

To compare the kinetics of RuBi-GABA uncaging and GABAergic synaptic events, we recorded somatic sucrose-evoked mIPSCs (Figure 3A, black), and spontaneous mIPSCs (Figure 3A, green) (see Materials and Methods) in the same conditions in which we performed RuBi-GABA uncaging experiments. On average,
GABA uncaging responses were significantly slower in rise and decay kinetics than endogenous synaptic currents. At the same time, as expected from diffusional delays, the exact site of uncaging impacted the amplitude, rise and decay time of the uncaging-evoked current (see below). Thus, by varying the position of the uncaging spot with respect to the neuron we were able to obtain currents that were somewhat similar in their time-topeak and decay time constants to endogenous GABAergic synaptic responses (Figure 3A, blue and Table 1).

As one would expect, the kinetics of the uncaging-induced responses were also determined by the length of the laser pulse used, since longer uncaging pulses generate a larger "cloud" of photoreleased compound (Figure 3B). After testing $5 \mathrm{~ms}$ (Figure 3B, cyan), $1 \mathrm{~ms}$, and $0.5 \mathrm{~ms}$ (Figure 3B, blue) pulses, we settled for $0.5 \mathrm{~ms}$ pulses to induce post-synaptic currents, and $5 \mathrm{~ms}$ pulses to prevent action potential firing (see below), although these are parameters that should be chosen depending on the exact experimental goals.

We studied the spatial resolution of RuBi-GABA visible light uncaging in voltage-clamp, by measuring the amplitude of the uncaging-evoked responses as a function of distance from the original peri-somatic uncaging spot. We characterized the axial ( $Z$-axis) resolution for $5 \mathrm{~ms}$ (cyan; $21.7 \mu \mathrm{m}$ at half-max) and $0.5 \mathrm{~ms}$ (blue; $16.2 \mu \mathrm{m}$ at half-max) uncaging pulses (Figure $3 \mathrm{C}$ ). As expected $0.5 \mathrm{~ms}$ provided better axial resolution than $5 \mathrm{~ms}$ uncaging pulses. The lateral resolution $(X / Y$-axes) was better than the axial resolution by a factor of 5 (Figure 3D). Both $5 \mathrm{~ms}$ and $0.5 \mathrm{~ms}$ pulses rendered similar lateral resolution results and the data were pooled $(3.5 \mu \mathrm{m}$ at half-max).
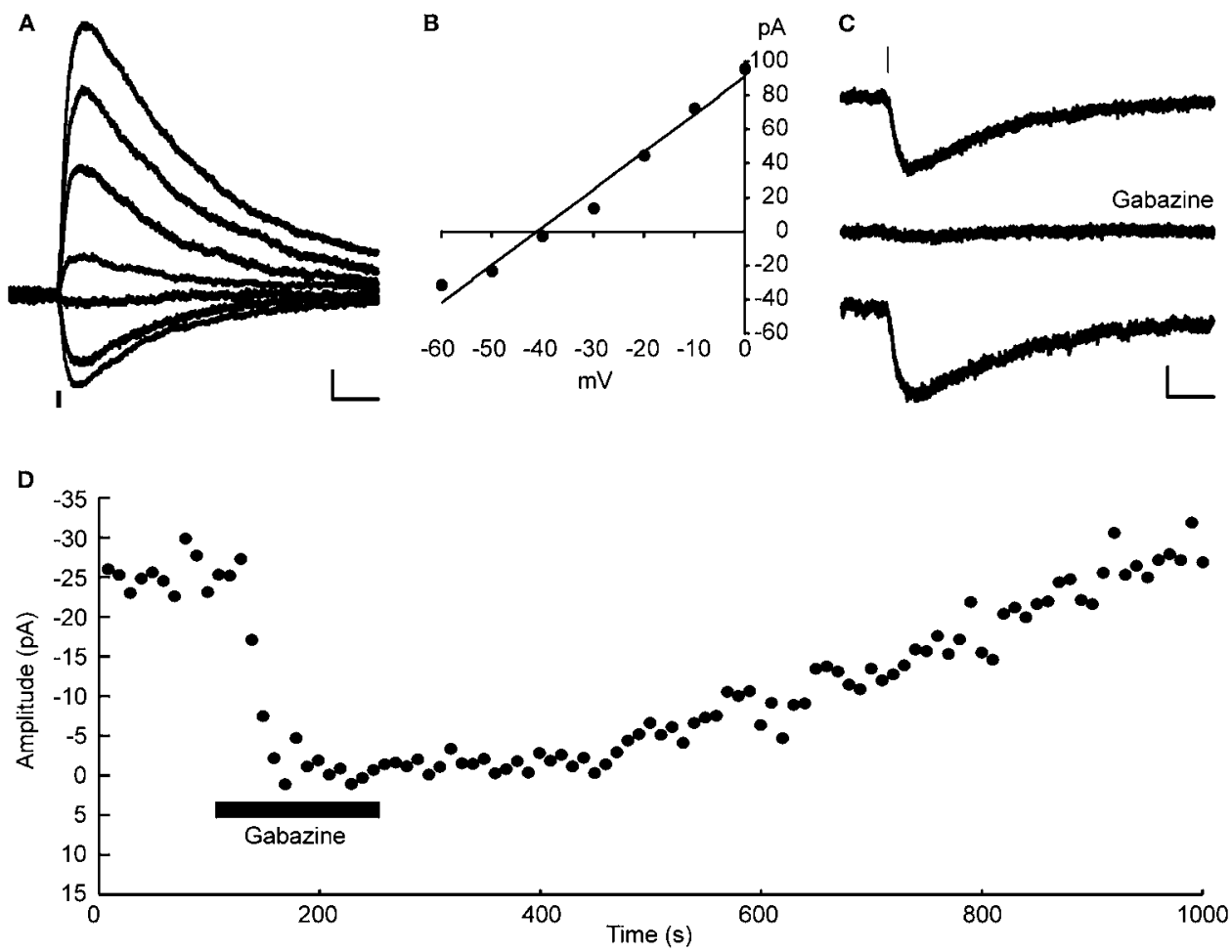

Figure 2 | RuBi-GABA uncaging activates GABA-A receptors. (A) RuBi-GABA uncaging responses collected at different holding potentials (every $10 \mathrm{mV}$ from 0 to $-60 \mathrm{mV}$ ) showing the uncaging-induced current reversal close to the expected chloride reversal $(-43 \mathrm{mV})$. The black bar below the traces indicates the uncaging laser pulse. (B) Current-voltage plot with a linear fit to the peak amplitudes shown in (D). (C) Average RuBi-GABA uncaging response before (top), during $20 \mu \mathrm{M}$ gabazine application (center), and after drug wash out (bottom). Responses were collected at $-70 \mathrm{mV}$ of holding potential in $\mathrm{K}^{+}-$based internal solution with $-40 \mathrm{mV}$ of chloride reversal. The black bar above the traces indicates the uncaging laser pulse. (D) Peak amplitude of uncaging responses as a function of time for the experiment shown in (C). Scale bars: $10 \mathrm{pA}, 50 \mathrm{~ms}$. 

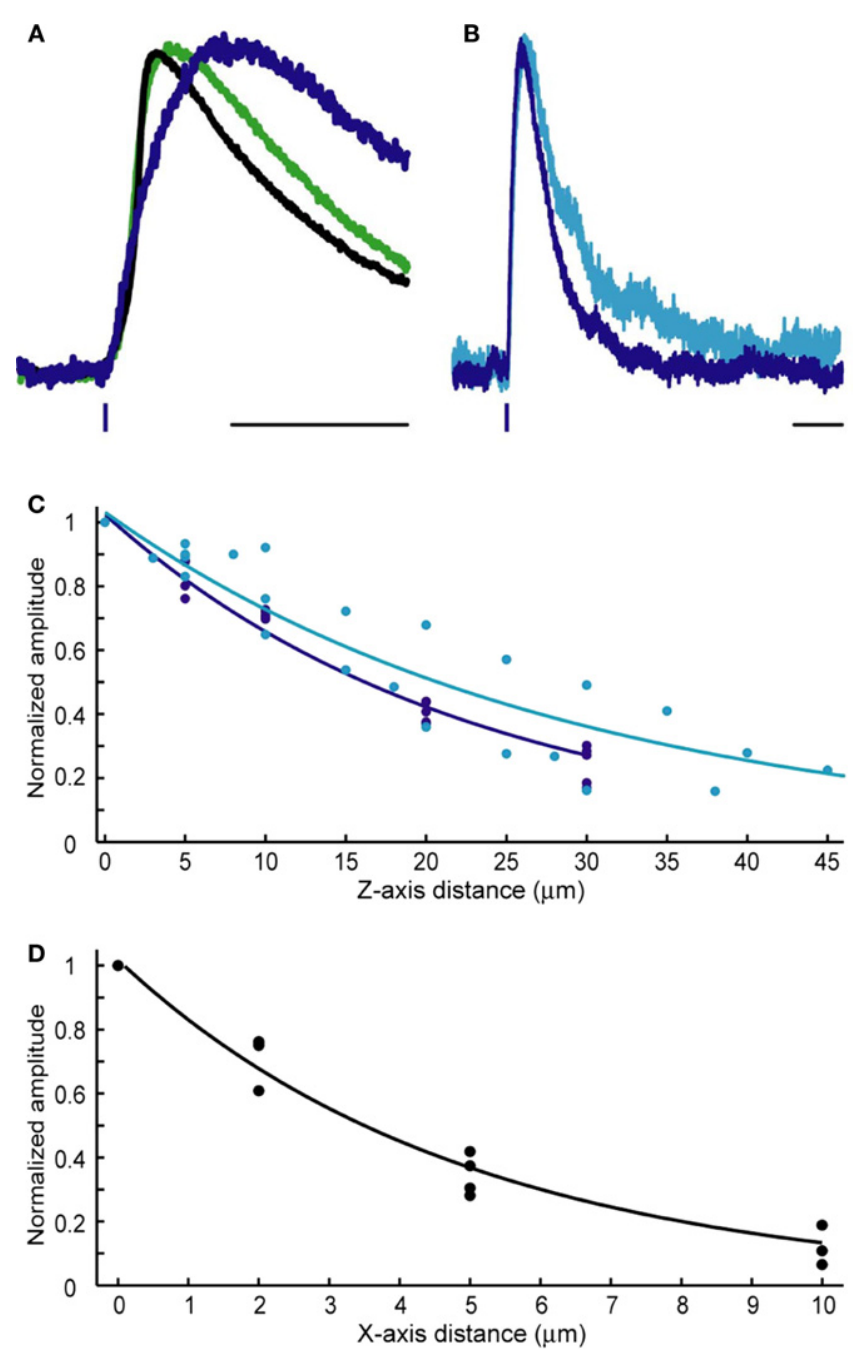

Figure 3 | Kinetics and spatial resolution of RuBi-GABA uncaging. (A) Scaled GABAergic responses. Average somatic mIPSC evoked by sucrose application (black), average mIPSC (green), and average uncaging response elicited by a $0.5 \mathrm{~ms} 473 \mathrm{~nm}$ laser pulse (blue). Scale bar: $20 \mathrm{~ms}$. (B) Slight difference in the kinetics shown by uncaging responses elicited by $5 \mathrm{~ms}$ (cyan) or $0.5 \mathrm{~ms}$ (blue) uncaging pulses. Scale bar: $50 \mathrm{~ms}$. (C) Axial (Z-axis) resolution of GABA uncaging using $5 \mathrm{~ms}$ (cyan) or $0.5 \mathrm{~ms}$ (blue) uncaging pulses. (D) Lateral (X/Y-axes) resolution of GABA uncaging. $5 \mathrm{~ms}$ and $0.5 \mathrm{~ms}$ laser pulses rendered similar resolution and the data were pooled. Lines in (C) and (D) show single exponential fits of the data.

\section{RuBi-GABA UNCAGING CAN BE USED TO MAP GABAergic RECEPTORS}

Unlike glutamatergic synapses, which are mostly located in dendritic spines, GABAergic synapses are not easily identifiable without pre-labeling them. Therefore, this makes the choice of a particular spot for GABA uncaging arbitrary, since, as we showed, moving the uncaging spot in the three dimensions generates responses with different kinetics and amplitudes, even when using the same uncaging power and laser pulse length. Nevertheless, despite the great variability in the kinetics of the uncaging responses, depending on the exact position of the uncaging spot along the peri-somatic region, some of these responses were somewhat similar to synaptic events (Figure 3A, blue and Table 1). Thus, by systematically probing different locations of neuronal membrane, researchers could study the effects of inhibition impinging at different regions of the neuron.

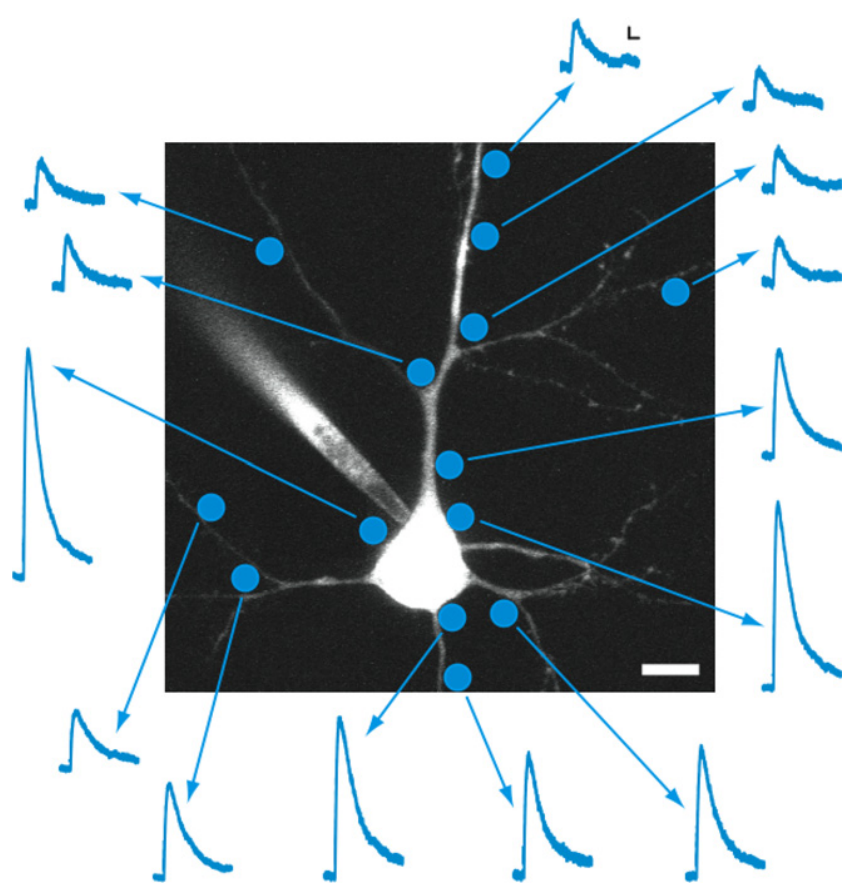

Figure 4 | Mapping GABAergic responses in individual neurons. Example of an experiment in which GABA receptor density mapping was attempted using $0.5 \mathrm{~ms}$ laser pulses of the same intensity at different positions along the cell body, dendrites, and axon of a layer $2 / 3$ pyramidal neuron in mouse visual cortex. This example illustrates practical advantages and limitations regarding the spatial resolution of the technique. Scale bars: $5 \mathrm{pA}, 50 \mathrm{~ms}, 10 \mu \mathrm{m}$.

As an example of this, we explored the responses generated by RuBi-GABA uncaging on different locations of the neuron by systematically probing the membrane of the soma, dendrites, and axon (Figure 4). To generate an accurate map, we ensured that no other processes belonging to the same neuron were $40 \mu \mathrm{m}$ above or below the uncaging site of interest. Thus, the recorded currents could be assigned to such uncaging site with 5-10 $\mu \mathrm{m}$ accuracy, the lateral resolution demonstrated before (Figure 3D). In these experiments, every tested position generated a response, although there were "hot spots" in the soma and dendrites, i.e., regions where the amplitude of the responses was differentially larger, compared with other locations (Figure 4).

\section{RUBi-GABA UNCAGING CAN BE USED TO OPTICALLY SILENCE NEURONS}

Besides its use to map GABAergic receptors in living neurons, another attractive application of GABA uncaging is to control the activity of cells to study their role on a neuronal network or circuit. To explore this, we investigated whether RuBi-GABA uncaging could be used to reversibly silence pyramidal neurons in a circuit, as it has been recently demonstrated with the expression of an archaebacterial-derived chloride pump (Zhang et al., 2007). In our experiments, we applied a sinusoidal current injection that would reliably make the cell fire an action potential and, in alternating trials, added a 5-ms uncaging pulse 5-10 ms before the action potential peak (Figure 5A). With this protocol we were able to reversibly prevent action potential generation using RuBi-GABA uncaging (Figures 5B,C,D). Specifically, we found that a 5-ms uncaging pulse, placed in an arbitrarily chosen peri-somatic spot, was sufficient to reliably prevent action potential firing. The efficacy of this optical 
Table 1 | Comparison of kinetics of physiological and uncaging responses.

\begin{tabular}{|c|c|c|c|c|c|c|c|}
\hline \multirow[t]{2}{*}{ Event type } & \multirow[t]{2}{*}{ Number of events (cells) } & \multicolumn{2}{|c|}{ Time to peak (ms) } & \multicolumn{2}{|c|}{ 20-80\% Rise speed (pA/ms) } & \multicolumn{2}{|c|}{ Decay time constant* (ms) } \\
\hline & & Median & $\operatorname{IQR}^{\dagger}$ & Median & $\operatorname{IQR}^{\dagger}$ & Median & $\operatorname{IQR}^{\dagger}$ \\
\hline Somatic mIPSCs & $1099(11)$ & 6.6 & $4.7-9$ & 2.4 & $1.49-4.54$ & 22.44 & $17.84-27.57$ \\
\hline mIPSCs & $380(3)$ & 6.8 & $5.25-9.15$ & 2.14 & $1.36-3.83$ & 33.37 & $27.62-38.79$ \\
\hline \multicolumn{8}{|c|}{ Uncaging responses } \\
\hline All events & $157(7)$ & 15.5 & $12.38-20.08$ & 2.17 & $1.59-3.02$ & 70.2 & $61.97-77.1$ \\
\hline $0.5 \mathrm{~ms}$ Pulse & $25(2)$ & 16.9 & $13.68-19.65$ & 1.49 & $0.98-2.59$ & 76.87 & $70.61-89.31$ \\
\hline $1 \mathrm{~ms}$ Pulse & $100(2)$ & 13.95 & $11.85-16.7$ & 2.28 & $1.68-3.01$ & 67.18 & $60.27-75$ \\
\hline $5 \mathrm{~ms}$ Pulse & $32(3)$ & 28.55 & $19.4-35$ & 2.39 & $1.93-3.86$ & 70.61 & $63.87-79.46$ \\
\hline
\end{tabular}

${ }^{*}$ Decay time constant measured using single exponential fit, ${ }^{+}$Inter-quartile range.
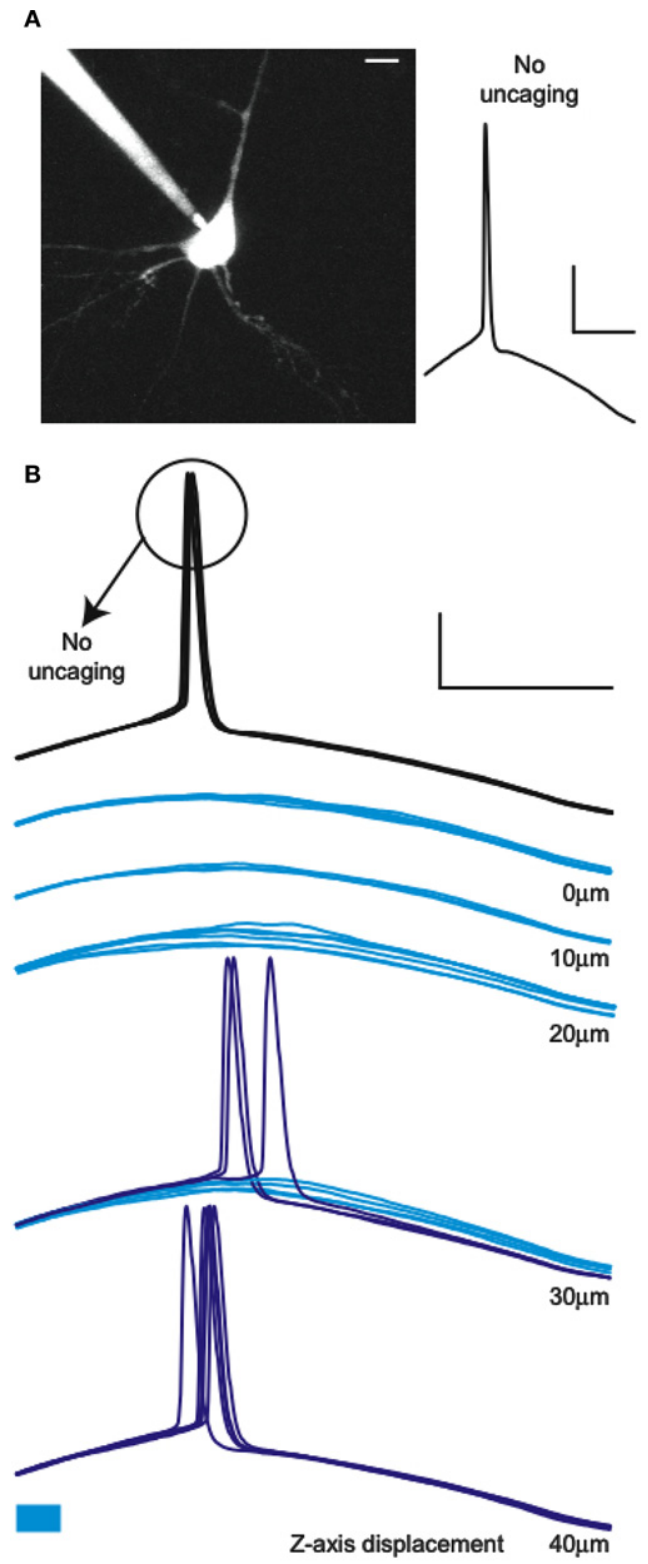

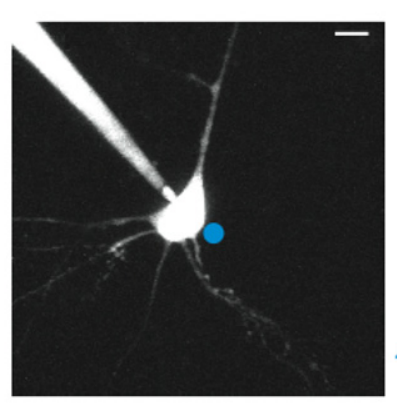

Uncaging

\section{c}
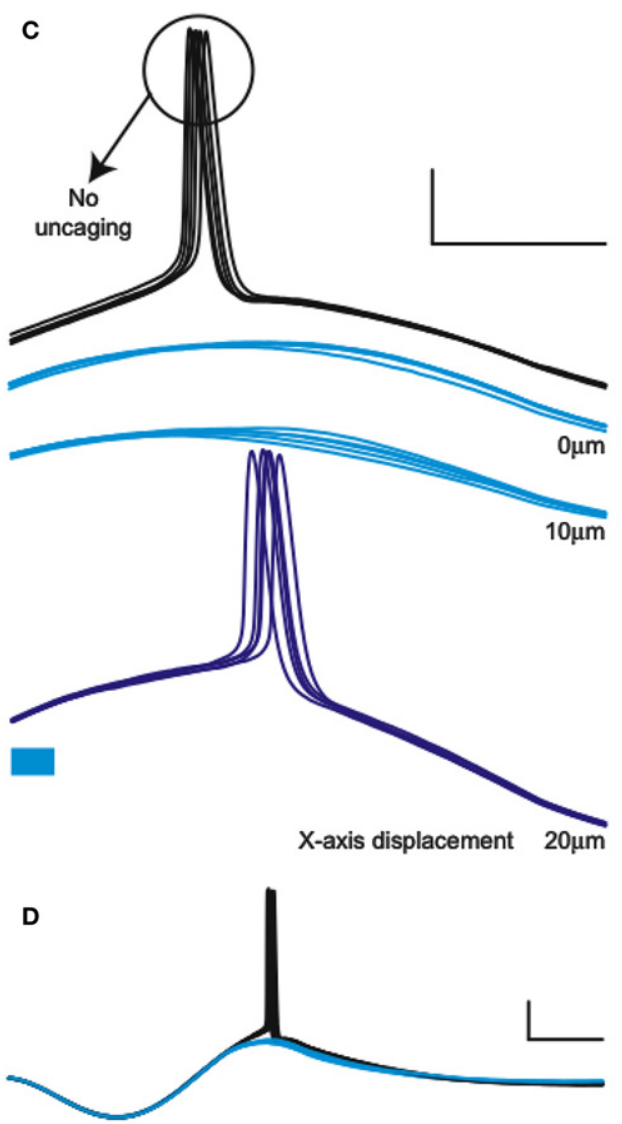

Figure 5 | Optical silencing of neurons with RuBi-GABA. (A) Schematic of the experiment showing the recorded neuron and two alternating trials, one with no uncaging (left, black) and one with uncaging pulse delivered to a peri-somatic spot (right, cyan),which abolishes the action potential (AP). (B) Example of an experiment in which $5 \mathrm{~ms}$ laser pulses were used to prevent AP firing of a layer 2/3 neuron in mouse visual cortex in response to a sinusoidal current injection. Cyan traces represent successful silencing, while the blue traces show the failures of silencing (therefore AP generation), illustrating a 30- $\mu \mathrm{m}$ axial resolution for this effect. (C) Same as (B), but illustrating the lateral resolution. Cyan bars below traces indicate the uncaging laser pulse. (D) Example of a full cycle sinusoidal stimulation with and without AP silencing due to RuBi-GABA uncaging. Scale bars: $20 \mathrm{mV}, 20 \mathrm{~ms}(\boldsymbol{A}-\boldsymbol{C}), 50 \mathrm{~ms}(\boldsymbol{D}), 10 \mu \mathrm{m}$. 
silencing was lost with distances to the cell ranging $25-70 \mu \mathrm{m}$ in the axial direction, and $20-40 \mu \mathrm{m}$ in the lateral direction $(n=6)$. These experiments demonstrated that RuBi-GABA can be used to optically gate neuronal firing of single or small groups of cells in cortical slices.

\section{DISCUSSION}

Here we introduce RuBi-GABA, the first caged compound, to our knowledge, that can be used to photorelease GABA with visible wavelengths. RuBi-GABA is based on a new inorganic photolabile protecting group, sensitive to visible light (Zayat et al., 2003, 2006). We show that RuBi-GABA produces GABA-A receptor-mediated currents. Also, its characterized spatial resolution shows the potential of this technique for GABAergic receptor mapping. Finally, we demonstrate how RuBi-GABA can be used to optically silence neurons. While we have only explored these two types of experiments, there are also other potential uses of RuBi-GABA: mapping GABAergic inputs arriving from various interneuron types, silencing of several neurons in various spatio-temporal patterns, mapping subcellular and cell type specific changes in reversal potential changes during epilepsy, etc.

In the past, UV glutamate uncaging has been successfully used to map circuits (Bureau et al., 2004; Callaway and Katz, 1993; Shepherd et al., 2003; Yoshimura et al., 2005). Likewise, several caged GABA compounds have been used, with UV excitation, to analyze the distribution and function of GABAergic contacts with low resolution (Katagiri et al., 2007; Pettit and Augustine, 2000; Wang and Augustine, 1995), or to prevent epileptic-like events in primary cultures (Rothman et al., 2007). RuBi-GABA presents several advantages compared to the currently available compounds for GABA uncaging. First, instead of UV, visible light can be used to photorelease GABA using the ruthenium caging group. Unlike UV, visible light is less damaging to DNA or proteins and does not seem to activate stress-response proteins and transcription factors (Trautinger et al., 1996; van der Wees et al., 2007). In addition, visible light penetrates farther into tissue than UV light, reducing the relative energy required to uncage as a function of depth. This difference in penetration, due to Rayleigh scattering, is inversely proportional to the 4 th power of the wavelength (Fowles, 1968). It is worth noting that, the resolution of RuBi-GABA visible light uncaging is superior to regular caged compounds and comparable to that of doublecaged glutamate compounds (Pettit et al., 1997). Furthermore, the higher quantum yield of RuBi-GABA (Zayat et al., 2007) also necessitates less uncaging energy. Finally, another advantage of using visible light for uncaging is the low cost of its uncaging light source. Powerful blue lasers are available at a fraction of the cost of the typical UV uncaging source, giving visible light uncaging wider applicability. In fact, we have carried out successful uncaging experiments with laser pointers and disposable camera flashes (not shown). Together, these spectral and yield advantages could translate into effective uses of rutheniumbased compounds for in vitro and in vivo applications, including its potential therapeutic uses to prevent or control epileptiform events in human patients.

More generally, our work expands the chemical toolbox of biological uncaging to include inorganic-based compounds, a potentially very useful approach, given the abundance of stable elements in the periodic table that are metals and, also, that their photochemistry is usually faster and more direct than the currently used organic nitrobenzyl-based photochemical cages (Balzani and Carassitti, 1970). Indeed, besides RuBi-GABA, we have used a similar chemical strategy to successfully cage many neuroactive compounds, such as 4AP, 5HT, nicotine, glycine and tetrazole glycine (Nikolenko et al., 2005; Zayat et al., 2003, 2006, Etchenique et al., unpublished results). The chemical versatility, fast photorelease and flexibility of wavelength choice make ruthenium-based uncaging an ideal chemical platform that could greatly help the optical interrogation of neuronal biophysics and the optical dissection of neuronal circuits.

\section{CONFLICT OF INTEREST STATEMENT}

The authors declare that the research was conducted in the absence of any commercial or financial relationships that could be construed as a potential conflict of interest.

\section{ACKNOWLEDGEMENTS}

We thank members of both laboratories for help and comments. Supported by the Kavli Institute for Brain Science, the National Eye Institute, the Fulbright Commission, CONICET, ANPCyT and the Office of Technology Ventures from Columbia University.

\section{REFERENCES}

Alger, B. E., and Nicoll, R. A. (1979). GABA-mediated biphasic inhibitory responses in hippocampus. Nature 281, 315-317.

Andersen, P., Dingledine, R., Gjerstad, L., Langmoen, I. A., and Laursen, A. M. (1980). Two different responses of hippocampal pyramidal cells to application of gamma-amino butyric acid. J. Physiol. 305, 279-296.

Balzani, V., and Carassitti, V. (1970). Photochemistry of Coordination Compounds. London, Academic Press.

Ben-Ari, Y. (2002). Excitatory actions of gaba during development: the nature of the nurture. Nat. Rev. Neurosci. 3, 728-739.

Ben-Ari, Y., Cherubini, E., Coradetti, R., and Gaiarsa, J. L. (1989). Giant synaptic potentials in immature rat CA3 hippocampal neurons. J. Physiol. (Lond.) 416, 303-325.

Bureau, I., Shepherd, G. M., and Svoboda, K. (2004). Precise development of functional and anatomical columns in the neocortex. Neuron 42, 789-801.

Callaway, E. M., and Katz, L. C. (1993). Photostimulation using caged glutamate reveals functional circuitry in living brain slices. Proc. Natl. Acad. Sci. USA 90, 7661-7665.

Canepari, M., Nelson, L., Papageorgiou, G., Corrie, J., and Ogden, D. (2001). Photochemical and pharmacological evaluation of 7-nitroindolinyl-and 4-methoxy-7-nitroindolinyl-amino acids as novel, fast caged neurotransmitters. J. Neurosci. Methods 112, 29-42.

Connors, B. W., Malenka, R. C., and Silva, L. R. (1988). Two inhibitory postsynaptic potentials, and GABAA and GABAB receptor-mediated responses in neocortex of rat and cat. J. Physiol. 406, 443-468.

Fowles, G. R. (1968). Introduction to Modern Optics, 2nd Edn. New York, NY, Dover Publications.

Gibson, J. R., Beierlein, M., and Connors, B. W. (1999). Two networks of electrically coupled inhibitory neurons in neocortex. Nature 402, 75-79.

Gulledge, A. T., and Stuart, G. J. (2003). Excitatory actions of GABA in the cortex. Neuron 37, 299-309.

Gupta, A., Wang, Y., and Markram, H. (2000). Organizing principles for a diversity of GABAergic interneurons and synapses in the neocortex. Science 287, $273-278$.

Janigro, D., and Schwartzkroin, P. A. (1988). Effects of GABA on CA3 pyramidal cell dendrites in rabbit hippocampal slices. Brain Res. 453, 265-274.

Katagiri, H., Fagiolini, M., and Hensch, T. K. (2007). Optimization of somatic inhibition at critical period onset in mouse visual cortex. Neuron $53,805-812$.

Khirug, S., Yamada, J., Afzalov, R., Voipio, J., Khiroug, L., and Kaila, K. (2008). GABAergic depolarization of the axon initial segment in cortical principal neurons is caused by the $\mathrm{Na}-\mathrm{K}-2 \mathrm{Cl}$ cotransporter NKCC1. J. Neurosci. 28, 4635-4639.

Maier, W., Corrie, J. E., Papageorgiou, G., Laube, B., and Grewer, C. (2005). Comparative analysis of inhibitory effects of caged ligands for the NMDA receptor. J. Neurosci. Methods 142, 1-9.

Molnar, P., and Nadler, J. V. (2000). gamma-Aminobutyrate, alpha-carboxy-2nitrobenzyl ester selectively blocks inhibitory synaptic transmission in rat dentate gyrus. Eur. J. Pharmacol. 391, 255-262. 
Nikolenko, V., Yuste, R., Zayat, L., Baraldo, L. M., and Etchenique, R. (2005). Twophoton uncaging of neurochemicals using inorganic metal complexes. Chem. Commun. (Camb.), 13, 1752-1754.

Pettit, D. L., and Augustine, G. J. (2000). Distribution of functional glutamate and GABA receptors on hippocampal pyramidal cells and interneurons. J. Neurophysiol. 84, 28-38.

Pettit, D. L., Wang, S. S., Gee, K. R., and Augustine, G. J. (1997). Chemical twophoton uncaging: a novel approach to mapping glutamate receptors. Neuron $19,465-471$.

Rothman, S. M., Perry, G., Yang, X. F., Hyrc, K., and Schmidt, B. F. (2007). Optical suppression of seizure-like activity with an LED. Epilepsy Res. 74, 201-209.

Shepherd, G. M., Pologruto, T. A., and Svoboda, K. (2003). Circuit analysis of experience-dependent plasticity in the developing rat barrel cortex. Neuron $38,277-289$.

Svaaland, L. O., and Ellingsen, R. (1983). Optical properties of human brain Photochem. Photobiol. 38, 293-299.

Szabadics, J., Varga, C., Molnar, G., Olah, S., Barzo, P., and Tamas, G. (2006) Excitatory effect of GABAergic axo-axonic cells in cortical microcircuits. Science 311, 233-235.

Taira, T.,Lamsa, K., and Kaila, K. (1997). Posttetanic excitation mediated by GABA(A) receptors in rat CAl pyramidal neurons. J. Neurophysiol. 77, 2213-2218.

Thompson, S. M., and Gahwiler, B. H. (1989). Activity-dependent disinhibition. I. Repetitive stimulation reduces IPSP driving force and conductance in the hippocampus in vitro. J. Neurophysiol. 61, 501-511.
Trautinger, F., Kindas-Mugge, I., Knobler, R. M., and Honigsmann, H. (1996). Stress proteins in the cellular response to ultraviolet radiation. J. Photochem. Photobiol. B, Biol. 35, 141-148.

van der Wees, C., Jansen, J., Vrieling, H., van der Laarse, A., Van Zeeland, A., and Mullenders, L. (2007). Nucleotide excision repair in differentiated cells. Mutat. Res. 614, 16-23.

Wang, S. S., and Augustine, G. J. (1995). Confocal imaging and local photolysis of caged compounds: dual probes of synaptic function. Neuron 15, 755-760.

Woodruff, A. R., Monyer, H., and Sah, P. (2006). GABAergic excitation in the basolateral amygdala. J. Neurosci. 26, 11881-11887.

Yoshimura, Y., Dantzker, J. L., and Callaway, E. M. (2005). Excitatory cortical neurons form fine-scale functional networks. Nature 433, 868-873.

Zayat, L., Calero, C., Albores, P., Baraldo, L., and Etchenique, R. (2003). A new strategy for neurochemical photodelivery: metal-ligand heterolytic cleavage. J. Am. Chem. Soc. 125, 882-883.

Zayat, L., Noval, M. G., Campi, J., Calero, C. I., Calvo, D. J., and Etchenique, R. (2007). A new inorganic photolabile protecting group for highly efficient visible light GABA uncaging. Chembiochem 8, 2035-2038.

Zayat, L., Salierno, M., and Etchenique, R. (2006). Ruthenium(II) bipyridyl complexes as photolabile caging groups for amines. Inorg. Chem. 45, $1728-1731$.

Zhang, F., Wang, L. P., Brauner, M., Liewald, J. F., Kay, K., Watzke, N., Wood, P. G., Bamberg, E., Nagel, G., Gottschalk, A., Deisseroth, K. (2007). Multimodal fast optical interrogation of neural circuitry. Nature 446, 633-639. 